\title{
GLAD!
}

Revue sur le langage, le genre, les sexualités

$03 \mid 2017$

Hétérosexualités

\section{Anne Garréta, Le moment Queer : désordonner le sexe}

Compte-rendu de conférence

\section{Alice Laumier}

\section{(2) OpenEdition}

\section{Journals}

Édition électronique

URL : http://journals.openedition.org/glad/822

DOI : $10.4000 /$ glad. 822

ISSN : 2551-0819

Éditeur

Association GSL

\section{Référence électronique}

Alice Laumier, « Anne Garréta, Le moment Queer : désordonner le sexe », GLAD! [En ligne], 03 | 2017, mis en ligne le 10 décembre 2017, consulté le 20 janvier 2021. URL : http://journals.openedition.org/glad/ 822 ; DOI : https://doi.org/10.4000/glad.822

Ce document a été généré automatiquement le 20 janvier 2021.

\section{(c)}

La revue GLAD! est mise à disposition selon les termes de la Licence Creative Commons Attribution -

Pas d'Utilisation Commerciale - Pas de Modification 4.0 International. 


\title{
Anne Garréta, Le moment Queer : désordonner le sexe
}

\author{
Compte-rendu de conférence
}

Alice Laumier

1 Anne Garréta a écrit plusieurs romans et enseigne la littérature en France et aux ÉtatsUnis. Son dernier livre Dans l'béton vient de paraître. Elle était invitée par Plurigenre et le Cerilac de Paris 7, le 12 octobre 2017, pour une rencontre-débat intitulée: «Le moment Queer : désordonner le sexe ».

2 Quand se pose la question de la traduction en français du terme " queer » et qu'Anne Garréta répond qu'il n'est pas forcément nécessaire de le traduire mais qu'on peut le prononcer [kyir] afin de conserver une forme d'étrangeté dans la francisation (et accessoirement d'embêter l'Académie française), le ton de la rencontre est donné.

3 Selon elle, il faudrait parler des moments Queer plutôt que du moment Queer puisqu'il s'agit de revenir conjointement sur les étapes importantes de la formation de la théorie Queer comme sur le mouvement qui n'a cessé de s'opérer entre les États-Unis et la France. L'histoire discontinue de ces transferts culturels qui jalonnent une élaboration théorique et pratique ne peut être appréhendée en dehors de ces effets d'importation et de retraduction, de ses rapports avec les études de genre et le French feminism. Ceci amène alors nécessairement à prendre en compte le rôle des institutions, comme l'université, et de la langue, comme freins ou agents accélérateurs de ces translations. Si les années 1990 marquent une série d'opérations importantes, voire fondatrices, pour la théorie Queer, cette dernière n'en est pas moins déjà présente dans le féminisme français des années 1970, particulièrement chez Monique Wittig qui participe alors à Questions féministes, ou bien encore chez Michel Foucault. C'est sur Monique Wittig qu'Anne Garréta va alors s'arrêter en retraçant un parcours fait lui aussi d'allers-retours entre deux langues et deux pays, mais aussi entre la théorie et la littérature. La Pensée straight est un exemple parfait de cette circulation transatlantique et de la temporalité singulière que connait la diffusion de la théorie Queer. Synthétisant d'abord les positions de Monique Wittig sur l'hétérosexualité comme logique et régime politique qui distribue les corps selon une certaine économie, produisant alors la 
binarité du genre, Anne Garréta en vient ensuite à la littérature comme opérateur d'un changement dans l'imaginaire des possibles. Potentiellement en avance sur les possibilités politiques, c'est par elle (par le biais d'un travail sur le langage et la fiction) que ce qui forme clôture et horizon pour l'imaginaire peut être déplacé et peut déborder la simple prise de conscience de l'existence d'un régime de sexage.

4 Afin de poursuivre cette réflexion sur la capacité de la littérature à créer du désordre, le dernier temps de la rencontre a été consacré au premier roman d'Anne Garréta, Sphinx. Publié en 1986, ce roman met en œuvre, à même la langue, la possibilité d'une suspension de la différence des sexes et non pas seulement la déconstruction de ce qui fonde leurs oppositions et assure leur stabilité. Double enjeu: tenter de former un dehors aux différences sexuelles, à leur identification, et créer un espace où les projections, les représentations des lecteurs et lectrices puissent être réfléchies et interrogées comme autant d'impensés et de déterminations inconscientes qui orientent la lecture. Ainsi, il s'agit de déjouer ce qui structure l'intelligibilité historicisée du récit sans que cette perturbation ne s'achève par un retour à l'ordre.

\section{BIBLIOGRAPHIE}

GARRÉTA, Anne. 2017. Dans l'béton. Paris : Éditions Grasset.

GARRÉTA, Anne. 1986. Sphinx. Paris : Éditions Grasset.

WITTIG, Monique. 2013. La Pensée straight. Paris : Éditions Amsterdam.

\section{INDEX}

Keywords : queer, history, translation, literature

Thèmes : Actualités

Mots-clés : queer, histoire, traduction, littérature

\section{AUTEUR}

\section{ALICE LAUMIER}

Alice Laumier est doctorante en littérature française à l'université Paris 3 Sorbonne-Nouvelle. Sa thèse porte sur le motif de l'après-coup dans la littérature contemporaine française. 